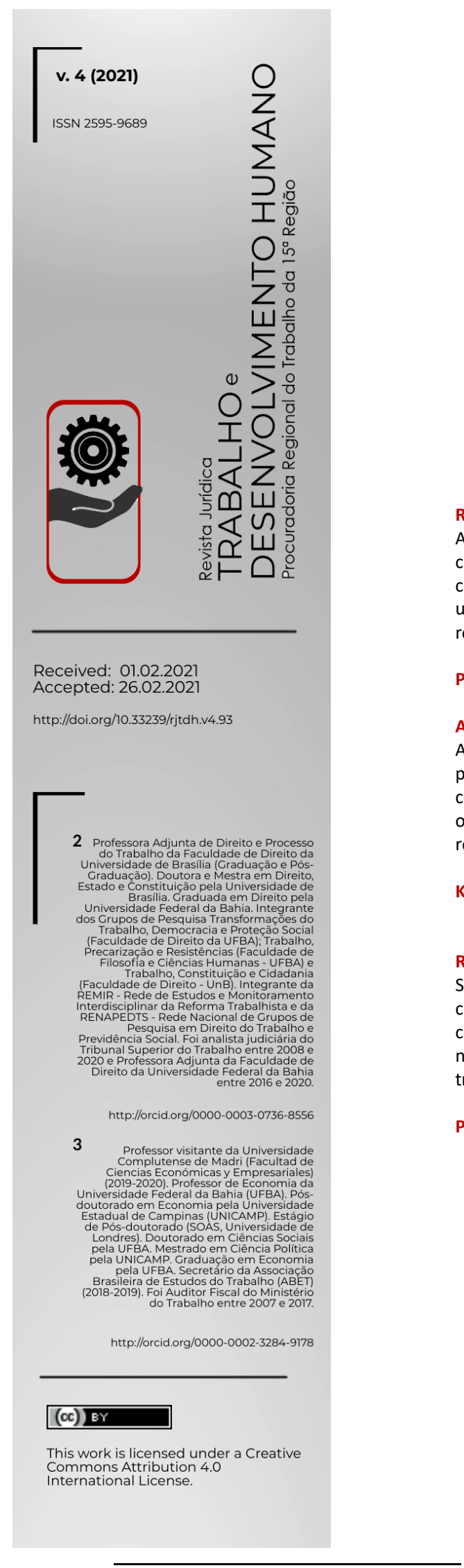

\title{
A polêmica sobre o conceito de terceirização e sua regulação ${ }^{1}$
}

The so-called outsourcing (subcontracting) question and its regulation

La polemica sobre el concepto de subcontratación (outscourcing) y su regulación

Renata Queiroz Dutra²

Vitor Araújo Filgueiras ${ }^{3}$

\begin{abstract}
RESUMO
Apesar de a terceirização ser objeto de grandes controvérsias, existe um consenso acerca do conceito que a define. $\mathrm{O}$ objetivo deste texto é problematizar esse consenso e apontar suas contradições, demonstrando que a precarização do trabalho relacionada à terceirização não é uma contingência, mas corolário da natureza dessa forma de contratação de trabalhadores, que reduz as chances de limitação da exploração do trabalho.
\end{abstract}

PALAVRAS-CHAVE: Terceirização, divisão do trabalho, precarização.

\section{ABSTRACT}

Although outsourcing (or subcontracting) has been subject of great controversy, there is predominant consensus over the concept that defines it. The aim of this paper is to discuss this consensus and point out its contradictions, indicating that the casualization of labour related to outsourcing is not a contingency, but corollary of the nature of this way of hiring workers, which reduces the chances of limiting labour exploitation.

KEYWORDS: Outsourcing, Division of labour, casualization.

\section{RESUMEN}

Si bien la subcontratación es objeto de importantes controversias, existe un consenso sobre el concepto que la define. El objetivo de este texto es problematizar este consenso y señalar sus contradicciones, demostrando que la precariedad del trabajo relacionada con la subcontratación no es una contingencia, sino un corolario de la naturaleza de esta forma de contratación de trabajadores, que reduce las posibilidades de limitar la explotación del trabajo.

PALABRAS CLAVE: subcontratación, división del trabajo, precariedad.

\footnotetext{
${ }^{1}$ Versão em português do artigo The so-called outsourcing (subcontracting) question and its regulation, publicado originalmente por Renata Queiroz Dutra e Vitor Araújo Filgueiras na Revista Direito e Práxis, v. 11, n. 4, pp. 25432571, dez. 2020. ISSN 2179-8966. A versão em português foi escrita pelos autores e é, neste ato, publicada com autorização da Revista Direito e Práxis.
} 
Revista Jurídica Trabalho e Desenvolvimento Humano

Procuradoria Regional do Trabalho da 15a Região

Introdução

Uma das principais estratégias de empresas capitalistas no mundo nas últimas quatro décadas tem sido adotar o que internacionalmente se chama de outsourcing ${ }^{2}$ ou subcontratação. No Brasil, o termo "terceirização" abarca ambos os termos: outsourcing e subcontratação. Esta estratégia de gestão afeta profundamente economias, políticas, mercados de trabalho, condições de trabalho e as vidas dos trabalhadores ao redor do globo.

Há várias abordagens analíticas para distinguir outsourcing de subcontratação. Por exemplo, o outsourcing pode ser descrito como uma relação de longo prazo, que normalmente acontece fora dos limites das empresas: "a rigor, o outsourcing se define como o desenvolvimento de uma fonte de abastecimento localizada fora de uma planta, uma fábrica ou uma filial responsável por produzir produtos finais e serviços" ${ }^{3}$. Neste caso, as fábricas onde smartphones são produzidos configuram bons exemplos de outsourcing.

A literatura geralmente afirma que "uma maior concorrência no mercado de produtos torna organismos do setor público e privado mais propensos a focar em atividades especializadas e 'externalizar' aspectos secundários do trabalho e da produção" ${ }^{4}$. Em outras palavras, o outsourcing pode ser definido como "uma transferência de atividades realizadas dentro de uma empresa para seus fornecedores que se tornou generalizada" ${ }^{5}$.

Entretanto, a subcontratação pode ser considerada no contexto de acordos para a execução de tarefas específicas por períodos mais curtos.

A subcontratação é um acordo entre duas unidades de produção, por meio do qual uma das unidades (a subcontratante) provê a outra (a principal), segundo termos e condições acordados, com produtos (peças ou produtos finais) que são usados ou comercializados pela unidade principal, sob sua exclusiva responsabilidade. Ordens de subcontratação podem incluir o processamento, a transformação ou o acabamento de materiais ou peças pelo subcontratante a pedido do contratante. A subcontratação pode ser

\footnotetext{
${ }^{2}$ Termo sem tradução literal para o português, mas seria algo como contratação externa.

3 ANDREFF, Wladimir. Outsourcing in the new strategy of multinational companies: foreign investment, international subcontracting and production relocation. Papeles de Europa, 18, 5-34. (Tradução do autor).

${ }^{4}$ WRIGHT, C.F. Beyond the employment relationship. Collective bargaining and supply chain coordination. TUC, 2011, p. 5. (Tradução do autor).

${ }^{5}$ DRAHOKOUPIL, Jan. The outsourcing challenge: organizing workers across fragmented production networks. (2015), Brussels: European Trade Union Institute, ISBN 978-2-87452-366-3. (Tradução do autor).
} 
Revista Jurídica Trabalho e Desenvolvimento Humano

doméstica, quando ambas as unidades funcionam no mesmo país; caso contrário, ela é internacional ${ }^{6}$.

Acordos geralmente realizados no setor da construção podem ilustrar o que é subcontratação. A definição oficial da ONU sobre subcontratação é:

Uma relação de subcontratação existe sempre que uma empresa (subcontratante) atua por conta de outra (contratante principal) durante $o$ processo de trabalho e execução de um produto específico, de acordo com planos e especificações técnicas fornecidas pelo contratante principal, que tem a responsabilidade econômica final ${ }^{7}$.

Apesar de serem dois termos diferentes para os quais as pessoas frequentemente tentam dar significados distintos, terceirização e subcontratação são essencialmente a mesma coisa. As definições e as diferenciações entre estas palavras podem variar, mas a essência de ambos os conceitos é a mesma: a transferência de atividades acessórias (ou menos importantes) de uma empresa para outra, normalmente uma empresa que esteja formalmente estabelecida. Geralmente, a externalização é o conceito fundamental que descreve ambas as palavras, adotado por empresas no sentido de focarem em seus negócios principais.

Outros autores também consideram a subcontratação e o outsourcing como um fenômeno único ${ }^{8}$. Não é uma coincidência que no Brasil o termo "terceirização" seja aplicado tanto para o que poderia se considerar subcontratação, quanto para outsourcing, e é também, predominantemente, definido como a externalização de alguma parte do processo de produção a ser contratada por outra unidade interessada. Portanto, a partir de agora, utilizaremos as três terminologias como sinônimas.

\footnotetext{
${ }^{6}$ UNCTAD, 1975, apud HALBACH, Axel J. Multinational enterprises and subcontracting in the third world: a study of inter-industrial linkages. In: Multinational Enterprises Programme Working Paper No. 58 (ILO). 01 January 1989. 92-2-107183-9[ISBN]. (Tradução do autor).

7 UNECE, 1995apud ANDREFF, Wladimir. Outsourcing in the new strategy of multinational companies: foreign investment, international subcontracting and production relocation. Papeles de Europa, 18, 5-34. (Tradução do autor).

8 "Usaremos os termos subcontratação, terceirização e desintegração vertical intercambiavelmente." (VAN LIEMT, Gijsbert. Subcontracting in electronics: From contract manufacturers to providers of Electronic Manufacturing Services (EMS). In: Sectoral Activities Programme Working Paper. International Labour Office, Geneva. April 2007. ISBN: 978-92-119906-9). (Tradução do autor).
} 
Revista Jurídica Trabalho e Desenvolvimento Humano

Procuradoria Regional do Trabalho da 15a Região

O objetivo deste texto, contudo, é mostrar que o que faz estas palavras essencialmente equivalentes não é o que se tornou o senso comum acerca da "terceirização". Nosso principal objetivo é fornecer um conceito coerente para este fenômeno. Desta forma, buscamos mostrar como o quadro regulamentar da "terceirização", que é mundialmente imposto, revela as limitações do conceito dominante, tendo como foco o caso brasileiro.

\section{Consenso e inconsistências do conceito dominante de terceirização ${ }^{9}$}

Defensores da terceirização argumentam que, no contexto atual, as empresas não podem se envolver diretamente em todas as etapas da produção como faziam durante o Fordismo. Atualmente, elas têm que focar a atenção em seu negócio principal e no aumento de sua produtividade, e então contratar outros agentes (normalmente outras empresas, embora o intermediário possa ser descrito de diferentes formas) para exercer as atividades menos importantes, nas quais estes intermediários são especializados. Ou seja, seus argumentos baseiam-se na ideia de que as empresas estão delegando a outrem a execução de atividades acessórias relacionadas a seus negócios.

Consultores de gestão aconselham empresas há muito tempo a focarem em suas 'competências principais' e terceirizarem outras atividades (e.g. Domberger 1998). A Globalização e a criação do Mercado Comum Europeu podem ter, de fato, tornado mais lucrativo para as empresas, a especialização no que elas sabem fazer de melhor (e.g. Meyer 2006) ${ }^{10}$.

Em todo o mundo, há muitas críticas à terceirização. Argumenta-se que este fenômeno mina as condições de trabalho, reduz os salários, aumenta os acidentes de trabalho etc. Inúmeros estudos realizados em vários países indicam que estas alegações são verdadeiras. Mas, mesmo quando são engajadas em lutas sérias contra as consequências da

\footnotetext{
${ }^{9} \mathrm{~A}$ formulação inicial do conceito de terceirização aqui adotado e desenvolvido A partir de novas situações empíricas e dinâmicas regulatórias constou originalmente em: FILGUEIRAS, Vitor Araújo; CAVALCANTE, Sávio. Terceirização: debate conceitual e conjuntura política. Revista da ABET (Impresso), v. 14, p. 15-36, 2015.

${ }^{10}$ DRAHOKOUPIL, Jan. The outsourcing challenge: organizing workers across fragmented production networks. (2015), Brussels: European Trade Union Institute, ISBN 978-2-87452-366-3. (Tradução do autor).
} 
terceirização, as críticas tendem a utilizar o mesmo entendimento conceitual usado pelos que defendem esta estratégia de gestão. Por exemplo, alguns autores apontam:

(...) mudanças radicais na estrutura de emprego no Reino Unido, particularmente na forma de transferência setorial, de setores tradicionais (incluindo o setor industrial e o setor público) para setores de serviços empresariais, ao passo que as atividades de serviço são retiradas de seus ambientes originais e transferidas para empresas em outras áreas da economia. Há inúmeras razões pelas quais empregadores escolhem terceirizar serviços, incluindo a possibilidade de focar nas funções essenciais e acessar serviços especializados, mas o desejo de reduzir custos é frequentemente um fator-chave. Esta demanda por serviços de custos mais baixos é transmitida para o fornecedor considerado eficaz, que deve cumprir as metas de qualidade do serviço de acordo com o preço estipulado em contrato, enquanto assegura a lucratividade do modelo de negócio. Há várias estratégias que fornecedores utilizam para atingir tais metas, incluindo: contenção salarial; redução da mão de obra, oferecendo o mesmo serviço, mas com menos empregados; ou contratação de número menor de empregados permanentes e uso de trabalhadores de agências ${ }^{11}$.

Sejam as consequências para os trabalhadores consideradas boas ou ruins, entendese que empresas distintas são responsáveis por vários elos da chamada cadeia produtiva (cadeia de suprimento ou cadeia de valor): "Diante de uma produção fragmentada, os produtores já não precisam controlar cadeias produtivas inteiras nem as organizar numa única empresa"12.

No entanto, empiricamente, a terceirização difere consideravelmente desta descrição. Invariavelmente, a empresa contratante dirige o processo de produção e o trabalho de acordo com suas necessidades. Há vários exemplos desta situação em empresas de todo o mundo e em todos os setores.

\footnotetext{
${ }^{11}$ HUWS, Ursula; PODRO, Sarah. Outsourcing and the fragmentation of employment relations: the challenges ahead. ACAS future of workplace relations discussion paper. August, 2012. Disponível em: www.acas.org.uk/. Acesso em: 20 abr. 2021. (Tradução do autor).

12 ANDREFF, Wladimir. Outsourcing in the new strategy of multinational companies: foreign investment, international subcontracting and production relocation. Papeles de Europa, 18, 5-34. (Tradução do autor).
} 
Revista Jurídica Trabalho e Desenvolvimento Humano

Procuradoria Regional do Trabalho da 15a Região

Várias pesquisas realizadas nas últimas décadas, envolvendo empresas de diversos países, demonstram que não importa como a terceirização é juridicamente disposta, a empresa contratante sempre controla a força de trabalho ${ }^{13}$.

Na terceirização, o comando das atividades permanece com a empresa contratante, que determina efetivamente quando, onde e como a produção ocorre. As formas de controle da mão de obra terceirizada podem variar um pouco entre contratantes e setores econômicos, e são fortemente influenciadas por aspectos do mercado de trabalho. Frequentemente, os métodos de controle são muito explícitos, sendo praticados como tradicionalmente fazem os empregadores. É muito comum, por exemplo, ver empresas clientes impondo nos contratos que elas possam escolher quem são os trabalhadores terceirizados. A citação a seguir, dos termos e condições de contratação de um trabalhador terceirizado no setor de limpeza britânico, oferece um bom exemplo desta situação:

Seu emprego conosco está sujeito à aceitação contínua por parte do nosso cliente, que tem o direito de recusar a sua admissão de acordo com as premissas. Caso isto ocorra, a Companhia reserva-se o direito de mudar o seu local de trabalho, disponibilizando-o em uma distância razoável do presente local de trabalho. (Tradução do autor).

Em outros casos, diferentes métodos de gestão são adotados, tais como o pagamento por atividade, a imposição de prazos, o monitoramento on-line, a realização de espécies de

\footnotetext{
${ }^{13}$ Por exemplo, MERCANTE, Carolina Vieira. A terceirização na indústria de confeç̧ões e a reincidência do trabalho análogo ao escravo. XIV Encontro Nacional da ABET. Campinas, setembro de 2015; FILGUEIRAS, Vitor Araújo. Estado e direito do trabalho no Brasil: regulação do emprego entre 1988 e 2008. Salvador, Tese de Doutoramento do Programa de Pós-graduação em C. Sociais/FFCH/UFBA, 2012; FILGUEIRAS, Vitor Araújo. Novas/Velhas formas de organização e exploração do trabalho: a produção "integrada" na agroindústria. Revista Mediações. Londrina, UEL, 2013; FILGUEIRAS, Vitor Araújo. Terceirização e trabalho análogo ao escravo: coincidência? 2014C. Disponível em: http://indicadoresderegulacaodoemprego.blogspot.com.br/2014/06/terceirizacaoe-trabalho-analogo-ao.html. Acesso em: 20 abr. 2021; FILGUEIRAS, Vitor Araújo. Terceirização e os limites da relação de emprego: trabalhadores mais próximos da escravidão e morte. Revista do $\mathbf{V}$ Congresso internacional de direito do trabalho e processo do trabalho de Santa Maria, 2014. v. 3. p. 20; DUTRA, Renata Queiroz. Do outro lado da linha: Poder Judiciário, regulação e adoecimento dos trabalhadores em call centers. São Paulo: LTr, 2014; FILGUEIRAS, Vitor Araújo; DRUCK, M. G. A epidemia da terceirização e a responsabilidade do STF. Revista do Tribunal Superior do Trabalho, v. 80, p. 106-125, 2014; FILGUEIRAS, Vitor Araújo; CAVALCANTE, Sávio. Terceirização: um problema conceitual e político. Le Monde Diplomatique, 2015. Disponível em: http://www.diplomatique.org.br/artigo.php?id=1799. Acesso em: 20 abr. 2021.
} 
Revista Jurídica Trabalho e Desenvolvimento Humano

Procuradoria Regional do Trabalho da 15a Região

leilões entre subcontratantes etc. Entretanto, de fato, eles têm o mesmo propósito e atingem os mesmos objetivos. Nas últimas décadas, a tecnologia tem ajudado bastante a implantar estas maneiras menos óbvias de gerenciar trabalhadores, ainda que, às vezes, sejam até mais atuantes do que a gestão tradicional. Certamente, em muitos casos, elas são utilizadas de forma intencional, uma vez que as empresas tentam evitar a legislação trabalhista, por exemplo.

A Toyota, paradigma e precursora do processo de terceirização contemporâneo, era dona de pequenas empresas subcontratadas nas quais o seu mecanismo de terceirização foi desenvolvido, ${ }^{14}$, e este não é um caso isolado no setor automotivo ${ }^{15}$. Estivemos, pessoalmente, em uma fábrica de automóveis onde os trabalhadores terceirizados que construíam os veículos eram diretamente selecionados e geridos pela empresa automobilística, que realizava um tipo de leilão entre os intermediários para conseguir a mão de obra mais barata ${ }^{16}$.

O setor de vestuário é outro bom exemplo que revela o que a terceirização realmente é. As principais marcas explicitamente argumentam que elas não produzem as mercadorias, apenas compram as roupas de fornecedores, sobre os quais elas não têm controle. Entretanto, algumas das maiores empresas de moda do mundo foram flagradas usando trabalho análogo

14 HIRATA apud DRUCK, Graça. 1999. Terceirização: (des)fordizando a fábrica: um estudo do complexo petroquímico. São Paulo: Boitempo, 1999.

15 MARCELINO, Paula Regina. Honda: terceirização e precarização: a outra face do toyotismo. In: ANTUNES. Ricardo (org.). Riqueza e miséria do trabalho no Brasil. São Paulo: Boitempo, 2007.

${ }^{16}$ Para este e outros exemplos de diferentes acordos no setor automotivo, veja FILGUEIRAS, Vitor Araújo; SOUZA, Ilan Fonseca. Criatividade do capital e exploração do trabalho no bojo da acumulação flexível: o esquema de intermediação da força de trabalho numa fábrica de veículo. Encontro nacional da ABET. João Pessoa, setembro 2011. Mas também é comum em outros setores, por exemplo: "Em uma ponta da cadeia, uma ou mais camadas de contratados fazem os produtos para uma marca, geralmente em outros países. A marca ou varejista principal impõe controles de preços que tornam quase impossível para os contratantes pagar aos trabalhadores que produzem bens na base da cadeia. Então, à medida que os produtos avançam na cadeia, o controle rígido do varejista sobre os preços coloca os subcontratados de licitações uns contra os outros, criando locais de trabalho inseguros e mal pagos em armazéns, portos e outros centros de distribuição de logística.". (RUCKELSHAUS, Catherine et al., Who's the Boss: Restoring Accountability for Labor Standards in Outsourced Work, National Employment Law Project, May 2014. Disponível em: http://www.nelp.org/page/-/Justice/2014/Whos-the-BossRestoring-Accountability-Labor-Standards-Out-Outsourced-Work-Report.pdf?nocdn=1). Acesso em: 20 abr. 2021. (Tradução do autor). 
Revista Jurídica Trabalho e Desenvolvimento Humano

Procuradoria Regional do Trabalho da 15a Região

ao escravo no Brasil. Em todos os casos, as investigações do Estado detectaram que a produção era controlada pelo contratante principal ${ }^{17}$.

O controle imposto pelo contratante principal no processo de trabalho e produção é também visto em acordos como os de franchising, como aponta Ruckelshaus et al.:

Franquias tipicamente ditam os termos dos acordos com seus franqueados, incluindo a cobrança de taxas exorbitantes pelo direito de operar seus negócios. Empresas líderes podem exercer um controle significativo sobre as operações diárias de seus franqueados. Os franqueadores podem ditar quantos trabalhadores são empregados em um estabelecimento, as horas que eles trabalham, como eles são treinados e como eles atendem ao telefone. Enquanto as marcas alegam que elas não têm qualquer influência sobre os salários pagos aos trabalhadores, elas controlam os salários fiscalizando todas as outras variáveis do negócio, exceto os salários. Recentes reportagens afirmam que os computadores do McDonald's rastreiam dados das vendas, balanços, e custos laborais, calculam a necessidade de mão de obra dos franqueados, estabelecem e fiscalizam seus horários de trabalho, inspecionam as revisões salariais dos franqueados e monitoram quanto tempo leva para os empregados atenderem ao pedido de cada cliente ${ }^{18}$.

Além disso, o McDonald's supostamente atua como um agenciador de mão de obra com poder de dispensar os empregados formais de suas franquias. $\mathrm{O}$ autor também afirma que a Domino's Pizza monitora o tempo de entrega dos empregados formais de seus franqueados, mantendo-os nos padrões da marca.

Até mesmo nos casos mais notórios e geograficamente fragmentados de terceirização, nos quais o intermediário pode apresentar lucros absolutos consideráveis, a produção é claramente controlada pela empresa contratante. Há relatórios detalhando como este esquema funciona: a marca famosa visa impor até a qualificação e o número de

\footnotetext{
17 Mercante mostra detalhes em MERCANTE, Carolina Vieira. A terceirização na indústria de confecções e a reincidência do trabalho análogo ao escravo. XIV Encontro Nacional da ABET. Campinas, setembro de 2015.

${ }^{18}$ RUCKELSHAUS, Catherine et al., Who's the Boss: Restoring Accountability for Labor Standards in Outsourced Work, National Employment Law Project, May 2014. Disponível em: http://www.nelp.org/page/Justice/2014/Whos-the-Boss-Restoring-Accountability-Labor-Standards-Out-Outsourced-WorkReport.pdf?nocdn=1). Acesso em: 20 abr. 2021. (Tradução do autor).
} 
Revista Jurídica Trabalho e Desenvolvimento Humano

Procuradoria Regional do Trabalho da 15a Região

trabalhadores necessários, no prazo e no modo que ela estipula ${ }^{19}$. Há uma hierarquia evidente no processo, totalmente regulada pela empresa contratante.

Portanto, a produção pode ser formalmente fragmentada e até mesmo geograficamente fragmentada, mas, de fato, a empresa contratante permanece no controle. Ela dirige o trabalho e o processo de produção e absorve a maior parte da riqueza social produzida.

No Reino Unido, o panorama não parece ser diferente. O setor de construção, por exemplo, apresenta uma boa visão do processo. Este setor, provavelmente, é um dos mais terceirizados. Há diferentes acordos de terceirização na construção, tais como contratar trabalhadores como autônomos através de agências, ou usando empresas de intermediação de força de trabalho. O que eles, finalmente, têm em comum é que a força de trabalho ainda é dirigida fundamentalmente pelo contratante principal. A diferença central entre os trabalhadores é apenas o modo como eles são contratados.

Em um local de construção que visitamos em Londres, e aparentemente não diferia da maioria das áreas de construção no Reino Unido ${ }^{20}$, havia 90 homens trabalhando, mas apenas 5 eram diretamente contratados pelo empreiteiro principal: 10 eram eletricistas, formalmente empregados por uma empresa terceirizada, 15 eram contratados como

\footnotetext{
19 “Em 2007, pouco mais de um mês antes do iPhone ser planejado para aparecer nas lojas, o Sr. Jobs chamou um punhado de tenentes para um escritório (...) O Sr. Jobs ergueu furiosamente seu iPhone, inclinando-o para que todos pudessem ver as dezenas de pequenos arranhões que estragavam sua tela de plástico (...) Não vou vender um produto que fica arranhado", disse ele tenso. A única solução era usar um vidro não quebrável. "Quero uma tela de vidro e a quero perfeita em seis semanas." (...) Quando uma equipe da Apple visitou, os proprietários da fábrica chinesa já estavam construindo uma nova ala. (...) Os proprietários disponibilizaram engenheiros quase sem custo. Eles construíram dormitórios no local para que os funcionários estivessem disponíveis 24 horas por dia. (...) "Eles poderiam contratar 3.000 pessoas durante a noite", disse Jennifer Rigoni, que era gerente de demanda de fornecimento mundial da Apple (...). "Qual unidade dos EUA pode encontrar 3.000 pessoas durante a noite e convencê-las a morar em dormitórios?" (...) Em meados de 2007, após um mês de experimentação, os engenheiros da Apple, finalmente, aperfeiçoaram um método para cortar vidro reforçado para que pudesse ser usado na tela do iPhone. (...) Outra vantagem crucial para a Apple era que a China fornecia engenheiros em uma escala que os Estados Unidos não podiam igualar. Os executivos da Apple estimaram que cerca de 8.700 engenheiros industriais eram necessários para supervisionar e orientar os 200.000 trabalhadores da linha de montagem, eventualmente envolvidos na fabricação de iPhones. Os analistas da empresa previram que levaria até nove meses para encontrar tantos engenheiros qualificados nos Estados Unidos". Ver, por exemplo, DUHIGG, Charles; BRADSHER, Keith. How the U.S. Lost Out on iPhone Work. New York Times, New York, January 21, 2012. Disponível em: http://www.nytimes.com/2012/01/22/business/apple-america-and-asqueezed-middle-class.html? $r=0$. Acesso em: 20 abr. 2021. (Tradução do autor).

${ }^{20}$ De acordo com dois engenheiros entrevistados no local de construção, aquela empresa era uma das poucas no setor que ainda empregava funcionários diretamente nos locais.
} 
funcionários de agências e 60 eram contratados como autônomos via agências. Alguns destes trabalhadores "autônomos", contratados através de agências, haviam trabalhado por quatro anos consecutivos para o empreiteiro principal. Aqueles que eram diretamente contratados eram, precisamente, os engenheiros e supervisores no topo da hierarquia no local de construção. Em outras palavras, aquelas pessoas que decidiam o que, onde, quando e como o trabalho deveria ser feito. Então, os operadores de guindaste, por exemplo, contratados como autônomos via agências, eram obrigados pelo contratante principal a trabalhar 10 horas por dia, ao invés do limite legal de 4 horas.

\section{A essência da terceirização}

A essência da terceirização é colocar alguma entidade entre trabalhadores e o capital, que lucra através do suor deles. Portanto, a terceirização é, especificamente, um fenômeno do mercado de trabalho. Não é uma questão de parcerias entre empresas diferentes, cada qual administrando seu próprio negócio, determinando suas próprias regras e maneiras de gerir a força de trabalho, trocando produtos ou serviços fora do mercado laboral (tal como na parceria entre um fornecedor de energia e uma fábrica de produtos químicos). Terceirização é sobre como a empresa organiza a sua própria mão de obra adotando uma forma diferente de contratar pessoal.

Outro aspecto da terceirização é que as empresas contratantes quase sempre detêm o know-how relevante, relativo às atividades. Isto porque estas atividades são parte de seu trabalho e processo de produção, e manter o know-how ajuda a impedir que o intermediário se torne o capital principal ou efetivo durante o processo. Isto também ocorre porque as posições-chave no controle e na hierarquia são ocupadas pela empresa contratante.

Em suma, a terceirização é uma estratégia de contratação de pessoal através de um intermediário, que é uma entidade interposta entre um trabalhador e um gestor efetivo do trabalho e da produção.

A configuração que a terceirização pressupõe pode variar de uma folha papel, como um documento declarando que o empregado é, agora, a "sua própria empresa", a entidades 
Revista Jurídica Trabalho e Desenvolvimento Humano

Procuradoria Regional do Trabalho da 15a Região

legais que podem formalmente empregar milhares de trabalhadores. No máximo, e em apenas muito poucos casos, o intermediário pode ser um sócio minoritário em um negócio controlado pela empresa cliente ${ }^{21}$. Em quaisquer circunstâncias, o controle da produção pertence à empresa dominante 22,23 .

As razões pelas quais o capitalista individual adota a terceirização podem diferir um pouco em cada caso, mas a principal intenção, diretamente calculada ou não, é aumentar os lucros, reduzindo as chances de a força de trabalho limitar a exploração. Assim, a terceirização tende a:

- Reduzir a resistência individual: A grande instabilidade e insegurança que caracterizam estes contratos tornam improvável que trabalhadores confrontem ordens e reclamem a respeito de qualquer questão. Ao mesmo tempo, também aumentam a subsunção do trabalho ao capital, já que os trabalhadores, muitas vezes, nem mesmo se reconhecem como parte do processo de produção do maior ou único beneficiário de seu trabalho.

- Minar ações coletivas: a terceirização normalmente dificulta aos trabalhadores a construção de identidades comuns com tipos diferentes de contrato, aumentando os obstáculos para uni-los. É também comum encontrar barreiras legais para realizar ações coletivas envolvendo empregados diretos e trabalhadores terceirizados.

- Enfraquecer a eficácia da regulamentação institucional: conforme o intermediário emerge como o suposto empregador, a responsabilidade geralmente não recai sobre a parte

\footnotetext{
${ }^{21} \mathrm{Em}$ alguns casos, os intermediários mais fortes foram utilizados para terceirizar, como no processo de produção "integrado" no setor agrário brasileiro. A força dos intermediários para gerenciar sua própria produção e enfrentar as empresas contratantes como iguais arruinou o arranjo. (FILGUEIRAS, Vitor. Novas/Velhas formas de organização e exploração do trabalho: a produção "integrada" na agroindústria. Revista Mediações. Londrina, UEL, 2013).

${ }^{22}$ Obviamente, o intermediário pode se tornar um capital efetivo em algum momento da relação. Nestes casos, já não falamos mais em terceirização, mas nas trocas mútuas de diferentes capitais que sempre ocorreram em sociedades capitalistas.

${ }^{23} \mathrm{Em}$ alguns acordos, os trabalhadores são "fornecidos" por intermediários para diferentes contratantes, possibilitando que o trabalhador trabalhe para empresas diferentes, através do mesmo intermediário. Nestes casos, não importa para a companhia quem vai fazer o trabalho, já que a maneira como os trabalhadores estão integrados no processo tem um papel fundamental em discipliná-los. Os intermediários são uma peça no jogo das empresas contratantes, e trocar um intermediário por outro é um dos principais movimentos neste jogo.
} 
principal, encarregada da situação dos trabalhadores, deixando a empresa contratante em uma posição confortável.

Nestas condições, as consequências da terceirização, que possibilitam que as empresas aumentem seus lucros, são geralmente as mesmas:

- Diminuir os custos: cortando salários, minando direitos trabalhistas, evitando ou reduzindo questões legais e relacionadas a sindicatos, tornando mais flexível e barato o gerenciamento de pessoal (demiti-los, deslocá-los, etc.).

- Aumentar a produtividade: os trabalhadores tendem a envidar mais esforços para atenuar suas condições precárias ${ }^{24}$, sendo menos propensos a fazer greves ou tirar qualquer tipo de folga do trabalho (tais como licença médica, intervalos de descanso no trabalho e descanso semanal).

\section{Precarização e terceirização "verdadeira" ou "falsa"}

A precariedade causada pela terceirização é conhecida no mundo todo. Empregos terceirizados são piores do que antes (quando eram feitos contratos diretos), e piores em comparação à situação das pessoas diretamente empregadas que permanecem realizando as mesmas atividades.

Para exemplificar, de acordo com Thebaud-Mony:

Vários trabalhos de pesquisa na Europa (Appay, Thébaud-Mony, 1997; Thébaud-Mony, 2000; BTS / Saltsa, 2000; Seillan; Morvan, 2005; Hery, 2009), Canadá (Lippel, 2004), Austrália (Quinlan, Mayhew, 1999, 2001) e Brasil (Druck; Franco, 2009) relatam o impacto do uso da terceirização e do trabalho temporário na saúde dos trabalhadores, a efetividade dos dispositivos de prevenção e a reparação de acidentes de trabalho e doenças ocupacionais ${ }^{25}$.

\footnotetext{
24 A situação dos entregadores é um bom exemplo deste processo. Contratados como autônomos, eles geralmente não têm salário fixo; são pagos por "taxas" de entrega, que podem chegar a ser menos do que o salário-mínimo, a depender do número de entregas. Ao precarizar, diminuir e desestabilizar completamente os salários, a empresa faz com que os entregadores tentem amenizar esta situação (ao menos, para sobreviver) trabalhando cada vez mais intensamente.

${ }^{25}$ THEBAUD-MONY, Annie. Precarização social do trabalho e resistências para a (re) conquista dos direitos dos trabalhadores na França. Caderno CRH, Salvador, v. 24, n. spe 01, 2011. (Tradução do autor).
} 
Até a Organização Internacional do Trabalho (OIT) expressou preocupação sobre a ligação entre terceirização e acidentes no trabalho. A título de exemplo, observe a pesquisa citada pela OIT:

Outros estudos indicam que a mão de obra empregada através de subcontratantes não é tratada da mesma forma que a mão de obra diretamente empregada, no que diz respeito à saúde e segurança. Pesquisas em nove grandes empresas de alto nível do setor de engenharia do Reino Unido identificaram um tratamento muito diferente para a mão de obra empregada através de subcontratantes, em comparação àqueles que foram empregados pelo contratante principal (Gyiet al., 1999). Sete das nove empresas prometeram exames admissionais para seus empregados (geralmente trabalhadores administrativos), mas apenas uma prometeu para os empregados de seus subcontratantes (sobretudo operários). Seis das empresas monitoravam a saúde de seus empregados, mas apenas duas monitoravam a saúde dos empregados de seus subcontratantes, e depois, apenas em projetos muito grandes. Somente um contratante principal assumiu que era responsável pelo pessoal empregado por subcontratantes ${ }^{26}$.

De acordo com o HSE - Health and Safety Executive, pesquisas demonstram "as implicações negativas para a segurança que emergem dos acordos de terceirização na indústria. Isto leva a problemas com responsabilidades indefinidas e dificuldades de comunicação entre um contratante e outro" 27 .

Em 2015, como parte de uma pesquisa no Reino Unido, inspecionamos dúzias de locais de construção em Londres, Leeds, Cardiff e Edinburgh para conferir as condições de segurança e saúde. Os locais normalmente tinham banheiros e instalações seguras, por exemplo, com proteção das bordas e andaimes bem estruturados. Havia situações de alta periculosidade em apenas 8 de 105 inspeções, e todos estes casos, sem exceção, envolviam trabalhadores terceirizados: eles não tinham proteção de altura, não tinham cordas, não tinham cintos de segurança; alguns deles não estavam nem usando capacetes. Ao mesmo tempo, grande número de trabalhadores no setor de construção era contratado através de

\footnotetext{
26 ILO. The construction industry in the twenty-first century: Its image, employment prospects and skill requirements. Tripartite Meeting on the Construction Industry in the Twenty-first Century: Its Image, Employment Prospects and Skill Requirements. Geneva, 2001, p. 36. (Tradução do autor).

${ }^{27}$ HSE. Causal factors in construction accidents. Prepared by Loughborough University and UMIST for the Health and Safety Executive, 2003, p. 69. (Tradução do autor).
} 
Revista Jurídica Trabalho e Desenvolvimento Humano

Procuradoria Regional do Trabalho da 15a Região

intermediários, como autônomos ${ }^{28}$, sendo impedidos de ter seus direitos trabalhistas respeitados e trabalhando em atividades muito instáveis e inseguras.

O cenário delineado pela terceirização também é precário para trabalhadores do setor de logística no Reino Unido. Empresas contratantes (tais como grandes bancos) realizam um tipo de leilão para conseguir os trabalhadores mais baratos, através de intermediários, reduzindo os salários ao mínimo. Falamos com vários trabalhadores de 6 intermediários diferentes, vimos documentos e equipamentos, e a situação parece ser ainda pior do que no setor de construção. Praticamente todos os trabalhadores são contratados como autônomos, impedindo-os de desfrutar de seus direitos trabalhistas (tais como licença médica e férias remuneradas), obrigando-os a pagarem taxas aos intermediários e, frequentemente, trabalharem sem nenhuma garantia mínima de pagamento.

Condições muito ruins de trabalho foram constatadas no setor de vestuário no Reino Unido. De acordo com pesquisas recentes realizadas pela Universidade de Leicester, há evidências consideráveis de que as estratégias de negócios no setor "são associadas a severas violações dos direitos trabalhistas", tais como o não pagamento de salários de acordo com o Salário Mínimo Nacional. “Estes problemas são endêmicos na indústria: relatórios, consistentemente, colocam o salário médio em $£ 3$ por hora e afirmam que isto se aplica de 75-90\% dos trabalhos no setor". Além disso, uma gama de violações, "de práticas de trabalho que resultam em problemas de saúde, padrões de saúde e segurança inadequados, abuso verbal, bullying, ameaças e humilhações, e a falta de intervalos para ir ao banheiro, entre outros." 29

Nos setores alimentício e de agricultura, o "retorno dos gangmasters" ${ }^{30}$ tem sido o modo predominante de terceirização, e parece ter aumentado a precariedade do trabalho e as formas mais extremas de exploração. Após a tragédia da Baía de Morecombe, a criação da

\footnotetext{
${ }^{28} \mathrm{Em}$ março de 2013, 39.2\% de toda a mão de obra da construção estava registrada como autônoma, grande parte contratada através de intermediários. (UK. Employment Status report. Office of tax simplification. March, 2015, p. 22).

${ }^{29}$ UK. Employment Status report. Office of tax simplification. March, 2015, p. 10. (Tradução do autor).

${ }^{30}$ ROGALY, Ben. Intensification of Workplace Regimes in British Horticulture: The Role Of Migrant Workers. Department Of Geography, Population, Space And Place, University Of Sussex, Vol. 14, 2008, p. 497-510. (Tradução do autor).
} 
Revista Jurídica Trabalho e Desenvolvimento Humano

Gangmaster License Authority (GLA) pareceu poder reduzir as más condições de trabalho. Entretanto, ao focar no intermediário, a GLA preservou o principal agente do processo (a empresa contratante), facilitando, desta maneira, a exploração contínua ${ }^{31}$. Até mesmo, a GLA admite que condições de trabalho análogas à escravidão aumentaram no Reino Unido nos últimos anos 32 .

No sentido de enfrentar a crítica, é muito comum ouvir defensores da terceirização dizendo que é necessário distinguir a terceirização legítima da falaciosa (ou a verdadeira da falsa). Para apoiar este argumento, eles também defendem a conceituação convencional, argumentando que, na terceirização genuína, o intermediário é especializado. Nesta perspectiva, o problema da precariedade laboral surgiria da terceirização falaciosa.

Contudo, pesquisas mostram que, se realizado legalmente ou ilegalmente, por empresas pequenas, médias, grandes ou gigantes, oferecendo empregos formais ou informais, empregos terceirizados têm condições inferiores de trabalho e são responsáveis pela grande maioria dos piores casos de exploração e acidentes de trabalho fatais ${ }^{33}$.

A questão mais expressiva deste debate está relacionada à divisão do trabalho. Ao afirmar que a terceirização é o aprofundamento da divisão do trabalho, o conceito tenta fazer com que o fenômeno pareça inexorável. A divisão do trabalho entre empresas sempre existirá em qualquer economia capitalista, onde empresas diferentes trocam bens e obtêm o excedente de seus próprios trabalhadores. Na verdade, se a terceirização fosse apenas o aprofundamento da divisão do trabalho capitalista, não haveria nada de substancialmente novo para dizer.

Entende-se, portanto, que o problema seria como a terceirização é executada, não o fenômeno em si. De fato, quão difícil é criticar e lutar contra a crescente produtividade

\footnotetext{
${ }^{31}$ FILGUEIRAS, Vitor Araújo; LIMA FILHO, Raymundo. 2015. O Ministério Púbico do Trabalho e a regulação do direito do trabalho no setor sucroalcooleiro de Sergipe. Anais do Encontro Nacional da ABET. Campinas, 2015. 32 GLA. Strategy for Protecting Vulnerable and Exploited Workers: 2015-2018. 2015.

33 FILGUEIRAS, Vitor Araújo. Terceirização e os limites da relação de emprego: trabalhadores mais próximos da escravidão e morte. Revista do $\mathrm{V}$ Congresso internacional de direito do trabalho e processo do trabalho de Santa Maria, 2014. v. 3; FILGUEIRAS, Vitor Araújo. Terceirização e trabalho análogo ao escravo: coincidência? 2014. Disponível em: http://indicadoresderegulacaodoemprego.blogspot.com.br/2014/06/terceirizacaoetrabalho-analogo-ao.html. Acesso em: 20 abr. 2021; FILGUEIRAS, Vitor Araújo. Terceirização: debate conceitual e conjuntura política. Revista da ABET (Impresso), v. 14, p. 15-36, 2015.
} 
derivada da divisão do trabalho e da especialização, se ela não necessariamente causa danos aos trabalhadores? A questão é que a precarização não é uma contingência, mas parte do processo, se entendermos a terceirização como uma estratégia de gestão para reduzir os limites à exploração.

\section{Contradições do conceito convencional de terceirização}

Conforme o argumento supracitado, no que diz respeito à inconsistência empírica, do conceito convencional de terceirização, há, pelo menos, duas contradições no discurso dominante que lançam luz sobre o real fenômeno.

Primeiramente, se a terceirização é o aprofundamento da divisão do trabalho, então os mercados deveriam ter se fragmentado, e agora estar divididos em companhias menores.

Vamos tomar o Reino Unido como exemplo. Entre 2000 e 2014, o número de empresas empregando 250 ou mais funcionários (consideradas como grandes), que são principalmente as empresas contratantes, cairam 6\%. Enquanto isso, o número total de empresas cresceu em $51 \%$, e o número de empresas sem empregados cresceu em $68 \%$. Este aumento da quantidade de empresas não empregadoras está muito relacionado às taxas de autônomos e às empresas não empregadoras, que estão diretamente associadas à terceirização. Consequentemente, no início de 2014, as pequenas empresas (0-49 funcionários) representavam 99.3\% das empresas existentes no Reino Unido.

No início dos anos 90, mais de 50\% dos empregos no Reino Unido estavam em grandes empresas ${ }^{34}$. Mas, em 2011, de acordo com a ONS - Office of National Statistics (UK), pequenas empresas (até 49 funcionários) representavam $46.2 \%$ dos empregos, em comparação a 41.2\% no caso de grandes empresas (mais de 250 funcionários). Em 2014, estes dados eram $47.9 \%$ e $39.9 \%$, respectivamente. Então, aparentemente, a fragmentação da produção é exatamente o que tem, de fato, acontecido durante a expansão da terceirização.

\footnotetext{
${ }^{34}$ De acordo com OECD, Database em SME statistics; Eurostat (1996), 53\% dos empregos no Reino Unido, em 1991, estavam em empresas contratantes de mais de 100 empregados.
} 
Uma maior proporção de pequenas empresas na população empresarial está empregando uma maior porcentagem de trabalhadores no mercado de trabalho.

Mas, apesar deste cenário, nas últimas décadas, o mundo tem visto, exatamente, o oposto acontecer. No Reino Unido, embora seja uma pequena minoria crescente de empresas registrando taxas de emprego cada vez mais baixas, as grandes empresas aumentaram os índices de faturamento entre 2011 e 2014 de 51.2\% para 53.2\%. No mesmo período, pequenas empresas viram seu faturamento cair de $34.9 \%$ para $33.2 \%$.

Como é possível explicar este processo aparentemente contraditório?

Pode-se dizer que: "Isso ocorre porque as empresas maiores aumentaram sua produtividade em comparação às menores". No entanto, um elevado número de trabalhadores registrados por empresas pequenas trabalha precisamente para empresas grandes através de intermediários. Inclusive, a responsabilidade das pequenas empresas sobre estes empregos aumentou à medida que a terceirização cresceu, então, mais pessoas são classificadas como funcionárias de pequenas empresas, embora continuem trabalhando para as grandes empresas.

A questão é que, enquanto são terceirizadas, estas pessoas continuam a ser, efetivamente, parte da força de trabalho das empresas para as quais elas continuam trabalhando, ou para as quais começaram a trabalhar. Em ambos os casos, como mão de obra subcontratada, independentemente do panorama apresentado pelo intermediário.

Em muitos casos, estamos falando exatamente das mesmas pessoas, nos mesmos trabalhos, trabalhando para a mesma empresa ${ }^{35}$. Então, os dados nos permitem reafirmar nossas hipóteses de que a terceirização não é apenas uma estratégia para gerenciar a força de trabalho, mas uma estratégia para gerenciar a força de trabalho que tende a amplificar a absorção da riqueza social produzida.

Neste sentido, é valido pensar sobre a questão a respeito dos trabalhadores autônomos, que em muitos casos são contratados por empresas através de terceirização ${ }^{36}$.

\footnotetext{
${ }^{35}$ SEELY, Antony. Self-employment in the construction industry. BRIEFING PAPER Number. 000196, 8 July 2015, p. 23-24.

${ }^{36}$ Atualmente, a chamada economia GIG prefere chamar os trabalhadores de autônomos em vez de usar figuras intermediárias.
} 
Se a maioria das pessoas classificadas como trabalhadores autônomos fosse, efetivamente, independente como agentes do mercado, negociando com outras empresas, elas tenderiam a aumentar seus índices na renda nacional (em comparação à situação prévia de empregados subordinados). No entanto, a OIT mostra que a participação deles na renda nacional de países ricos tem caído nos últimos anos. Diferentes fontes corroboram este indicador em relação ao Reino Unido, observando que a renda média do trabalhador autônomo é menor do que a renda dos trabalhadores empregados, e que esta diferença tem aumentado. Além disso, os autônomos têm ganhado menos fora do trabalho ultimamente ${ }^{37}$.

Portanto, este processo de migração da produção de grandes empresas para pequenos negócios e do status de empregado para autônomo contratado (frequentemente através de intermediários) não parece ocorrer na prática, mas é a apresentação formal de uma estratégia subjacente.

Se há uma centralização de capital, o conceito de terceirização como externalização do conceito de produção (aprofundando a divisão do trabalho) não resiste.

A segunda contradição do conceito tradicional de terceirização é ainda mais óbvia: se a terceirização é uma estratégia de gestão para focar no negócio principal e aumentar a especialização, como podem as empresas contratantes tentar terceirizar todos os seus trabalhadores? No Reino Unido, por exemplo, muitas empresas não têm funcionários ${ }^{38}$. Em que elas se especializam? E o mesmo procede para os intermediários: se, em muitos casos, eles não têm funcionários, então, em que eles são especializados?

As empresas líderes continuam "encolhendo" seus "negócios principais" porque querem fazer com seus empregados diretos remanescentes o que fazem com os terceirizados, ou seja, gerir os trabalhadores como se eles não fossem funcionários.

\footnotetext{
${ }^{37} \mathrm{O}$ aumento da renda do autônomo vindo apenas do trabalho: autônomo com renda de investimento, i.e. propriedade, juros, dividendos: $2000=63 \% ; 2013=35 \%$.

38 De acordo com a pesquisa citada por por Drahokoupil, no Reino Unido $23 \%$ de todas as empresas usam terceirização. Destas empresas, $49 \%$ terceirizam completamente suas atividades. (DRAHOKOUPIL, Jan. The outsourcing challenge: organizing workers across fragmented production networks. (2015), Brussels: European Trade Union Institute, ISBN 978-2-87452-366-3). (Tradução do autor).
} 
A retórica contraditória revela o real teor da polêmica sobre o conceito terceirização, que é provavelmente a principal estratégia de gestão de mão de obra na atual fase do capitalismo.

\section{O avanço da terceirização no Brasil: controvérsias jurídicas}

Também na América Latina os debates conceituais sobre a terceirização persistem, havendo significativa discussão a respeito das terminologias aplicáveis ao fenômeno. Persiste nas legislações dos países latino-americanos dissenso quanto ao emprego das expressões intermediação de mão de obra, subcontratação de produtos e serviços e subcontratação de mão de obra, como apontam Uriarte e Colotuzzo, havendo critérios e consequências jurídicas diversas para o enquadramento de fenômenos similares ${ }^{39}$.

Os autores entendem externalização, categoria genérica mais ampla, como todas aquelas formas de organização do trabalho em que a empresa recorre a trabalhadores que são real ou ficticiamente externos. Reconhecem os autores, a partir do arcabouço teórico e jurídico verificado na América Latina, que as dificuldades de uniformização conceitual tendem a inviabilizar a produção de normatização internacional sobre o tema, bem como tendem a aprofundar o caráter precarizante do fenômeno ${ }^{40}$.

Segundo eles, um dos elementos fulcrais para o crescimento das formas de contratação terceirizadas, ao lado da crise do modelo tradicional de empresa, das demandas por competitividade e da sua vinculação ao crescimento da economia informal (tão típica dos países latino-americanos), seria justamente o ambiente ideológico jurídico, no qual se percebe uma certa preferência pelas formas de contratação assemelhadas ao direito civil, em detrimento dos sistemas de proteção trabalhistas ${ }^{41}$.

\footnotetext{
${ }^{39}$ URIARTE, Ermida; COLOTUZZO, Natalia. Descentralización, tercerización, subcontratación. Lima: OIT, Proyecto FSAL, 2009. p. 202.

${ }^{40}$ URIARTE, Ermida; COLOTUZZO, Natalia. Descentralización, tercerización, subcontratación. Lima: OIT, Proyecto FSAL, 2009. p. 202.

${ }^{41}$ URIARTE, Ermida; COLOTUZZO, Natalia. Descentralización, tercerización, subcontratación. Lima: OIT, Proyecto FSAL, 2009. p. 202.
} 
Portanto, na raiz da abertura para a terceirização está o papel de uma vertente ideológica muito específica, a de colocar os sistemas jurídicos a serviço da privatização do direito laboral. Isso se afirma numa perspectiva mais ampla, que tem se concretizado mais recentemente com a absorção da figura do empreendedorismo e das falsas prestações de serviços autônomas por aplicativos, mas que teve sua manifestação original desde a década de 1990, com foco na permissividade de modos mais amplos de terceirização e seu consequente afastamento dos parâmetros protetivos do direito do trabalho.

No Brasil, a figura fora pautada desde o final da década de 1980 por ideólogos do liberalismo, que a definiam como forma de especialização das empresas para incremento de sua eficiência: a proposta atenderia a uma suposta tendência à proliferação de empresas pequenas, com poucos trabalhadores, e à reconhecida redução dos custos laborais promovida pela terceirização ${ }^{42}$. Para esses autores, a atuação das empresas em rede e a divisão de tarefas e atividades entre elas não necessariamente poderia ser encaixada nos critérios distintivos de atividades acessórias e principais, razão por que já vinham criticando o critério adotado pela jurisprudência brasileira na década de 1990, consubstanciado na permissividade da terceirização de atividades-meio e vedação das terceirizações de atividades-fim (Súmula no 331 do TST).

Nessa linha, duas questões parecem ser relevantes para a análise do caso brasileiro: primeiro, a centralidade da categoria do emprego para qualquer possível aferição da compatibilidade da terceirização com a ordem jurídica, elemento que, em verdade, justificou a adoção dos critérios da atividade fim e meio na década de 1990 e que, por isso mesmo, subsiste à sua derrogação pelo STF no julgamento da ADPF no 324 .

Segundo, o fato de que a categorização realizada no direito brasileiro sobre terceirização de atividade-fim e meio conviveu com outras categorizações que passaram ao largo do padrão regulatório estabelecido, de modo que, longe de encerrar a questão, abriu margem para que possibilidades tangentes fossem praticadas sem incidência da regulação protetiva ou com incidência diversa: nessa linha, os contratos de empreitada e os contratos

\footnotetext{
42 Por todos: PASTORE, José. Terceirização: uma realidade desamparada pela lei. Rev. TST, Brasília, vol. 74, no 4, out/dez 2008, p. 117-135.
} 
de facção, que, embora promovam arranjos triangulares de trabalho, foram entendidos como assimiláveis a figuras do direito civil e do direito empresarial, respectivamente, adquirindo posição refratária à tutela protetiva trabalhista, consubstanciada no contrato de trabalho.

Nessa segunda chave, é interessante perceber, por um lado, a seletividade da argumentação favorável ao uso das formas jurídicas civilistas e empresariais e, por outro, a recusa à juridicização dos caracteres ordinários da terceirização, permitindo aos defensores dessa prática o uso de expressões como "terceirização boa" e "terceirização ruim", de modo a tratar os dados concernentes à precarização promovida pela contratação terceirizada (já citados nesse artigo e consolidados na literatura) como externalidades acidentais e não inerentes ao fenômeno, e, por isso mesmo, afastadas das preocupações centrais do fenômeno jurídico.

Para enfrentar a primeira questão, é importante ter em mente, para além das ideias de "divisão do trabalho" ou especialização empresarial, o fato de que a terceirização promove uma dissociação entre a relação econômica de trabalho e a relação jurídica que lhe corresponde $^{43}$. A partir dessa conceituação, e tendo em vista que a categoria central do emprego definida na legislação brasileira e referência central para a aplicabilidade de todos os demais institutos do direito do trabalho, define-se, por opção legislativa, aferindo-se, a partir da primazia da realidade (e, portanto, a despeito de outras formalidades), a presença de pessoalidade, não eventualidade, onerosidade e subordinação jurídica na prestação de serviços, pode-se depreender limites legais ao fenômeno.

Estava dado, dessa forma, o limite legal à dissociação entre a relação econômica e a relação jurídica correspondente: ainda que a jurisprudência pretendesse uma reinterpretação da legislação apta a promover a abertura para a terceirização, esta somente poderia caminhar nas hipóteses em que os elementos do emprego direto não se perfizessem. Daí desdobraramse os conceitos de atividade-meio e atividade-fim, muito logicamente, eis que identificada a dificuldade (ou impossibilidade) de efetivação de terceirização de atividades-fim em algum nível de controle e poder (contrafaces da subordinação) por parte do tomador de serviços.

\footnotetext{
${ }^{43}$ DELGADO, Maurício Godinho. Curso de Direito do Trabalho. São Paulo: LTr, 2019.
} 
Revista Jurídica Trabalho e Desenvolvimento Humano Procuradoria Regional do Trabalho da 15a Região

Desse modo, quando declarado pelo STF em 2018 que "É lícita a terceirização ou qualquer outra forma de divisão do trabalho entre pessoas jurídicas distintas, independentemente do objeto social das empresas envolvidas, mantida a responsabilidade subsidiária das empresas contratantes" ${ }^{44}$, se, por um lado, resultam suprimidos os óbices jurisprudenciais quanto à natureza das atividades que poderiam ser terceirizadas (antiga redação da Súmula no 331 do TST), por outro, evidentemente que a tutela jurídica dessa assim denominada "divisão do trabalho" deve respeitar os enquadramentos jurídicos trabalhistas e empresariais que persistem em vigor na ordem jurídica.

Vale perceber que os pressupostos e a forma de aferição da relação de emprego não foram alterados pela reforma trabalhista de 2017 (Leis no 13.429 e 13.467), que alargou as hipóteses de terceirização. Portanto, é novamente a subordinação jurídica, em suas releituras consentâneas com as transformações pelas quais passaram o mundo do trabalho após a reestruturação produtiva pós-fordista, o elemento apto a definir a incidência da proteção trabalhista. Nesse ponto, insustentável a contradição de absorver o fenômeno da terceirização com base na argumentação de que as relações de produção se transformaram e que o direito do trabalho precisa se renovar para absorvê-las, e o mesmo não ser feito em relação aos institutos que podem vir a indicar vetores de proteção, a fim de pensar novas dimensões - objetivas, reticulares e estruturais - da subordinação.

Nessa mesma linha, o fenômeno da subordinação jurídica e sua contraface, que é o exercício do poder empresarial, tem sido considerado nas novas arquiteturas produtivas e de mercado para produção de diversos efeitos jurídicos. Sobretudo para efeito da preservação das relações concorrenciais e da segurança das transações capitalistas, tem-se observado no campo empresarial o reconhecimento de sujeitos de direitos que decorrem dos novos arranjos empresariais, ainda que sem a correspondente formalização societária. Ana Frazão observa, por exemplo, o reconhecimento jurídico de prerrogativas e responsabilidades para as denominadas joint ventures contratuais, que constituem arranjos empresariais firmados

${ }^{44}$ BRASIL. Supremo Tribunal Federal. Ação de descumprimento de preceito fundamental no 324 . Recurso Extraordinário (RE) no 958.252. Relator: Ministro Roberto Barroso. Pesquisa de Jurisprudência, Acordãos, 31 agosto 2018. Disponível em: http://portal.stf.jus.br/processos/downloadPeca.asp?id=15341024987\&ext=.pdf. Acesso em: 20 abr. 2021. 
por meio de contratos, que aparecerem justamente em face da realidade econômica de "esgotamento (hollowing-out) da grande empresa e a importância cada vez maior da desverticalização, da terceirização (outsourcing), das redes entre empresas (networks), bem como da precedência dos mecanismos de mercado sobre os movimentos de internalização e integração das grandes estruturas burocráticas" ${ }^{45}$.

Assim, observa a autora que, no âmbito do Direito Empresarial, a figura jurídica das joint ventures, enquanto aglomerados empresariais ligados por relações contratuais, tem sido reconhecida para efeitos de atuação conjunta no mercado e em relação à possibilidade de responsabilização e assunção de obrigações, a partir da identificação dos seus centros de controle e comando ${ }^{46}$.

Outrossim, o mesmo fenômeno se impõe como desafio no âmbito das relações de trabalho estabelecidas a partir desses novos arranjos: observam Uriarte e Colottuzo, que a consequência mais importante da terceirização no âmbito trabalhista é reconhecer que não há mais coincidência entre empresa e empregador, colocando-se o desafio de identificar o real empregador entre as diversas empresas integrantes de uma cadeia produtiva, a despeito de quem figure enquanto empregador formal ${ }^{47}$.

No âmbito do direito do trabalho, novos instrumentos, inclusive chancelados e ampliados pelas reformas trabalhistas, como o reconhecimento de grupos econômicos por coordenação, com responsabilização solidária dos integrantes das cadeias produtivas e aptidão para reconhece-los como um empregador único, caminham no mesmo sentido já trilhado pelo direito empresarial no sentido de entender que a mera "divisão do trabalho" entre empresas, configurando novos arranjos produtivos em rede, configuram concentração de poder e comando empresarial em conglomerados, e não alternância de empregadores. Igualmente, não podem se dissociar do binômio poder-responsabilidade, forma jurídica tão eficiente na preservação das relações concorrenciais entre capitais ${ }^{48}$.

\footnotetext{
45 FRAZÃO, Ana. Joint ventures contratuais. RIL Brasília a. 52 n. 207 jul./set. 2015 p. 187-211.

${ }^{46}$ FRAZÃO, Ana. Joint ventures contratuais. RIL Brasília a. 52 n. 207 jul./set. 2015 p. 187-211.

${ }^{47}$ URIARTE, Ermida; COLOTUZZO, Natalia. Descentralización, tercerización, subcontratación. Lima: OIT, Proyecto FSAL, 2009, p. 202.

${ }^{48}$ FRAZÃO, Ana. Grupos societários no direito do trabalho e a reforma trabalhista. Rev. TST, São Paulo, vol. 83, no 4, out/dez 2017.
} 
Assim, ficam evidenciadas as contradições do próprio discurso jurídico quando se demonstra que os novos arranjos ora são assimilados para transações capitalistas seguras, ora são convenientemente apontados como óbices à atribuição de responsabilidades trabalhistas ou mesmo culpabilizados pelo nível de emprego, como aventado na decisão do STF que declarou a permissividade de toda e qualquer terceirização. Isto é, para além das distorções conceituais entre a realidade e o discurso dos defensores da terceirização, tem-se, ainda, as importantes contradições reveladas no próprio discurso jurídico.

Por último, vale observar que a realidade empírica reiteradamente detectada em pesquisas, quanto ao aprofundamento da precarização do trabalho promovido pela terceirização, tem sido refutada no seio do discurso jurídico que chancela a terceirização: para a argumentação hegemônica, a terceirização não seria um mal em si. Do contrário, seria o seu mal-uso o responsável pelas situações de desrespeito aos direitos trabalhistas verificadas entre os trabalhadores terceirizados. Em verdade, com desfaçatez, os defensores da terceirização costumam narrar situações hipotéticas ou excetivas em que a terceirização é vantajosa para os trabalhadores ${ }^{49}$.

Daí porque a relevância de juridicizar os indicadores produzidos pela terceirização, e que são consensuais nos estudos sociológicos, inclusive naqueles promovidos pelos organismos internacionais de proteção ao trabalho.

Nesse sentido, é válido reconhecer o esforço Gabriela Neves Delgado e Helder Amorim quando passam a atribuir à terceirização aquilo que denominaram de rarefação dos direitos trabalhistas. É que, embora o arranjo jurídico promotor da terceirização assegure a persistência de uma relação de emprego entre a empresa prestadora de serviços e o trabalhador, tal arranjo não é suficiente para evitar que os direitos trabalhistas que decorrem do vínculo de emprego sofram uma depreciação ou esmaecimento, seja em seu valor material, seja na sua própria exequibilidade $\mathrm{e}^{50}$.

O percurso conceitual da literatura revela seu acerto sobretudo porque, se na década de 1990, os discursos favoráveis à terceirização se construíam com amparo na ideia de

\footnotetext{
49 PASTORE, José. Terceirização: uma realidade desamparada pela lei. Rev. TST, Brasília, vol. 74, no 4, out/dez 2008, p. 117-135.

${ }^{50}$ DELGADO, Gabriela Neves; AMORIM, Helder. Os limites constitucionais da terceirização. São Paulo: LTr, 2014.
} 
externalização de atividades acessórias, tendo por objetivo o incremento do desempenho das empresas em suas atividades principais ou finalísticas (o chamado core business), garantindo especialização e competividade no mercado global, essa construção argumentativa se esvaiu como uma cortina de fumaça quando o discurso empresarial que dominou o Congresso Nacional em 2017 com sua agenda foi o de que as empresas, para serem realmente eficientes e competitivas, precisariam terceirizar todas as suas atividades, inclusive aquelas principais e finalísticas, nas quais, duas décadas atrás, pretendiam se concentrar.

O interesse empresarial na terceirização fica escancarado: é a redução de custos, a diminuição dos níveis de responsabilidade e a flexibilidade que se alcança, em matéria de contratação, desligamento e gestão da força de trabalho, o que realmente interessa no arranjo terceirizante.

De fato, é isso que os dados têm insistentemente demonstrado: a terceirização aparece como forma de gestão de trabalho por aquele que supostamente terceiriza. Intensifica-se a dominação, duplica-se a subordinação (agora exercida pela empresa tomadora e pela empresa prestadora de serviços), forja-se um consentimento do trabalhador em relação a práticas cada vez mais predatórias (que o tornam mais descartável, mais vulnerável, mais suscetível aos comandos patronais); ao passo que se reduzem custos e responsabilidade daquele que, sem deixar de exercer as prerrogativas de empregador, se blinda dos ônus jurídicos daí decorrentes.

A lógica de flexibilidade que orientou o regime de acumulação após a reestruturação produtiva e a racionalidade neoliberal que o preside encontram na terceirização um instrumento apto à concretização de sua agenda: trabalhadores reduzidos, da condição de sujeitos de contratos de trabalho, a objetos silenciosos de contratos empresariais de prestação de serviços, alheados de seus coletivos de trabalho, fragilizados em suas identidades, pertencimentos e vínculos de solidariedade: portanto, mais vulneráveis do que nunca a esse poder patronal que se multiplica.

Mais que isso, a lógica da terceirização banaliza e naturaliza seu mecanismo perverso: com o tempo, os não terceirizados passam a entender que a precariedade e a descartabilidade do trabalho terceirizado é inevitável, e as responsabilidades morais, políticas, econômicas, 
dialógicas e até jurídicas pela degradante condição desses empregados pertence sempre a quem não está visível, a quem está fora do alcance, de modo a encerrar ou adormecer os conflitos coletivos de trabalho.

Para o direito do trabalho, a narrativa é de um alheamento desse grupo de trabalhadores em relação ao seu manto protetivo, que, aliás, tem sido cada vez mais restrito. Enfrentar a terceirização enquanto categoria jurídica paradoxal e contraditória em relação aos percursos institucionais já trilhados pelo direito do trabalho, explorando alternativas para os comandos disruptivos dela emanados pressupõe um enfrentamento conceitual que, assimilando o fenômeno, permita trazê-lo para a regulação do trabalho a partir de ferramentas que os próprios sistemas jurídicos já oferecem.

Nesse sentido, a conclusão recorrente das pesquisas sociológicas de que não se verifica empiricamente a prática da terceirização sem a manutenção de algum nível de subordinação entre trabalhadores e empresa principal torna insuperável a contradição entre o padrão de regulação jurídica brasileiro, que permitiu a terceirização de atividades-fim ao mesmo tempo em que preservou o seu conceito original de relação de emprego (employment). Sendo irreal a prática de terceirização de atividade-fim sem algum nível de subordinação e sendo a subordinação o elemento central para a definição da relação de emprego direta, a ordem jurídica brasileira se coloca em franca contradição ao legitimar a terceirização exatamente naquelas hipóteses em que a afirmação da relação empregatícia direta é imperativa.

\section{Conclusões}

Definimos outsourcing, subcontratação e terceirização como um conceito único: uma estratégia de contratação de trabalhadores através de um intermediário, que é uma entidade interposta entre um trabalhador e o gestor efetivo do trabalho e do processo de produção. Este, por sua vez, pode ser formalmente nomeado de várias formas, mas é geralmente apresentado como uma empresa. 
Revista Jurídica Trabalho e Desenvolvimento Humano

Procuradoria Regional do Trabalho da 15a Região

No que se refere a cada empresa individualmente, razões muito específicas para adotar a terceirização podem variar um pouco a cada caso. Mas, a principal intenção, diretamente calculada ou não, é aumentar os lucros, reduzindo as chances de a força de trabalho limitar a exploração. Isto ocorre porque terceirização e piores formas de exploração do trabalho estão fortemente relacionadas.

A terceirização não é um mecanismo para aprofundar a divisão social do trabalho. Como demonstrado ao longo deste artigo, o aumento da terceirização não corresponde a uma efetiva atribuição de tarefas a terceiros, tampouco a uma distribuição de capital em empresas menores. Na verdade, pesquisas mostram que empresas terceirizadas mantêm o controle e, consequentemente, a subordinação direta dos trabalhadores, assim como o aprofundamento do fenômeno da terceirização corresponde a um reforço à atuação e à concentração de capital em empresas maiores.

De fato, o falso argumento da divisão social do trabalho, que orientou a decisão do Supremo Tribunal Federal (STF) a respeito da terceirização, tem criado confusão nas discussões sobre trabalho em relação a outros temas além da terceirização. Ele tem sido invocado, por exemplo, para justificar arquiteturas jurídicas fraudulentas impostas pela economia GIG, que desrespeitam os direitos trabalhistas e não obedecem a compromissos fiscais, simulando a contratação de trabalhadores autônomos, sob o pretexto de externalizar, ou não diretamente realizar, suas atividades econômicas principais.

Isso é o que a Uber faz: enquanto vendem-se como uma empresa de logística, a maior empresa de transporte não se reconhece como uma empresa de transporte, mas como uma mera mediadora da relação entre consumidores e motoristas autônomos, não arcando com as responsabilidades que figuram um vínculo empregatício. Também não diz respeito à divisão social do trabalho, mas à sua distorção como uma maneira de driblar a legislação. Cabe mencionar que a economia GIG normalmente se difere da terceirização (ela apenas terceiriza se o " $a p p$ " utilizar intermediários para contratar trabalhadores), embora se baseie no discurso de divisão do trabalho para minar as uniões de trabalhadores e seus direitos.

Outra abordagem conceitual para terceirização é urgentemente necessária para aqueles buscam promover um trabalho digno. Com base no conceito convencional de 
terceirização, instituições tendem a direcionar o foco regulamentar nos intermediários e deixar as empresas principais em uma posição confortável para administrar despoticamente sua mão de obra, sistematicamente, perpetuando condições deploráveis de trabalho.

\section{Referências}

ANDREFF, Wladimir. Outsourcing in the new strategy of multinational companies: foreign investment, international subcontracting and production relocation. Papeles de Europa, 18, 5-34.

BRASIL. Supremo Tribunal Federal. Ação de descumprimento de preceito fundamental no 324 . Recurso Extraordinário (RE) no 958.252. Relator: Ministro Roberto Barroso. Pesquisa de Jurisprudência, Acordãos, 31 agosto 2018. Disponível em: http://portal.stf.jus.br/processos/downloadPeca.asp?id=15341024987\&ext=.pdf. Acesso em: 20 abr. 2021.

DELGADO, Gabriela Neves; AMORIM, Helder. Os limites constitucionais da terceirização. São Paulo: LTr, 2014.

DELGADO, Maurício Godinho. Curso de Direito do Trabalho. São Paulo: LTr, 2019.

DRAHOKOUPIL, Jan. The outsourcing challenge: organizing workers across fragmented production networks. (2015), Brussels: European Trade Union Institute, ISBN 978-2-87452366-3.

DRUCK, Graça. 1999. Terceirização: (des)fordizando a fábrica: um estudo do complexo petroquímico. São Paulo: Boitempo, 1999.

DUHIGG, Charles; BRADSHER, Keith. How the U.S. Lost Out on iPhone Work. New York Times, New York, January 21, 2012. Disponível em: http://www.nytimes.com/2012/01/22/business/apple-america-and-a-squeezed-middleclass.html? $r=0$. Acesso em: 20 abr. 2021.

DUTRA, Renata Queiroz. Do outro lado da linha: Poder Judiciário, regulação e adoecimento dos trabalhadores em call centers. São Paulo: LTr, 2014.

FILGUEIRAS, Vitor Araújo; CAVALCANTE, Sávio. Terceirização: debate conceitual e conjuntura política. Revista da ABET (Impresso), v. 14, p. 15-36, 2015. 
FILGUEIRAS, Vitor Araújo; CAVALCANTE, Sávio. Terceirização: um problema conceitual e político. Le Monde Diplomatique, 2015. Disponível em:

http://www.diplomatique.org.br/artigo.php?id=1799. Acesso em: 20 abr. 2021.

FILGUEIRAS, Vitor Araújo; DRUCK, M. G. A epidemia da terceirização e a responsabilidade do STF. Revista do Tribunal Superior do Trabalho, v. 80, p. 106-125, 2014.

FILGUEIRAS, Vitor Araújo; LIMA FILHO, Raymundo. 2015. O Ministério Púbico do Trabalho e a regulação do direito do trabalho no setor sucroalcooleiro de Sergipe. Anais do Encontro Nacional da ABET. Campinas, 2015.

FILGUEIRAS, Vitor Araújo; SOUZA, Ilan Fonseca. Criatividade do capital e exploração do trabalho no bojo da acumulação flexível: o esquema de intermediação da força de trabalho numa fábrica de veículo. Encontro nacional da ABET. João Pessoa, setembro 2011.

FILGUEIRAS, Vitor Araújo. Estado e direito do trabalho no Brasil: regulação do emprego entre 1988 e 2008. Salvador, Tese de Doutoramento do Programa de Pós-graduação em C. Sociais/FFCH/UFBA, 2012.

FILGUEIRAS, Vitor Araújo. Novas/Velhas formas de organização e exploração do trabalho: a produção "integrada” na agroindústria. Revista Mediações. Londrina, UEL, 2013.

FILGUEIRAS, Vitor Araújo. Terceirização: debate conceitual e conjuntura política. Revista da ABET (Impresso), v. 14, p. 15-36, 2015.

FILGUEIRAS, Vitor Araújo. Terceirização e os limites da relação de emprego: trabalhadores mais próximos da escravidão e morte. Revista do $\mathbf{V}$ Congresso internacional de direito do trabalho e processo do trabalho de Santa Maria, 2014. v. 3. p. 20

FILGUEIRAS, Vitor Araújo. Terceirização e trabalho análogo ao escravo: coincidência? 2014. Disponível em: http://indicadoresderegulacaodoemprego.blogspot.com.br/2014/06/terceirizacaoetrabalho-analogo-ao.html. Acesso em: 20 abr. 2021.

FRAZÃO, Ana. Grupos societários no direito do trabalho e a reforma trabalhista. Rev. TST, São Paulo, vol. 83, no 4, out/dez 2017.

FRAZÃO, Ana. Joint ventures contratuais. RIL Brasília a. 52 n. 207 jul./set. 2015 p. 187-211.

GLA. Strategy for Protecting Vulnerable and Exploited Workers. 2014-2017. 2014

GLA. Strategy for Protecting Vulnerable and Exploited Workers: 2015-2018. 2015. 
Revista Jurídica Trabalho e Desenvolvimento Humano

Procuradoria Regional do Trabalho da 15a Região

HALBACH, Axel J. Multinational enterprises and subcontracting in the third world: a study of inter-industrial linkages. In: Multinational Enterprises Programme Working Paper No. 58 (ILO). 01 January 1989. 92-2-107183-

9[ISBN].https://www.ilo.org/empent/Publications/WCMS 126358/lang--en/index.htm

HSE. Causal factors in construction accidents. Prepared by Loughborough University and UMIST for the Health and Safety Executive, 2003.

HUWS, Ursula; PODRO, Sarah. Outsourcing and the fragmentation of employment relations: the challenges ahead. ACAS future of workplace relations discussion paper. August, 2012. Disponível em: www.acas.org.uk/. Acesso em: 20 abr. 2021.

ILO. 2001. The construction industry in the twentyfirst century: Its image, employment prospects and skill requirements. Tripartite Meeting on the Construction Industry in the Twenty-first Century: Its Image, Employment Prospects and Skill Requirements. Geneva, 2001.

MARCELINO, Paula Regina. Honda: terceirização e precarização: a outra face do toyotismo. In: ANTUNES. Ricardo (org.). Riqueza e miséria do trabalho no Brasil. São Paulo: Boitempo, 2007.

MERCANTE, Carolina Vieira. A terceirização na indústria de confecções e a reincidência do trabalho análogo ao escravo. XIV Encontro Nacional da ABET. Campinas, setembro de 2015.

PASTORE, José. Terceirização: uma realidade desamparada pela lei. Rev. TST, Brasília, vol. 74, no 4, out/dez 2008, p. 117-135.

ROGALY, Ben. Intensification of Workplace Regimes in British Horticulture: The Role Of Migrant Workers. Department Of Geography, Population, Space And Place, University Of Sussex, Vol. 14, 2008, p. 497-510.

RUCKELSHAUS, Catherine et al., Who's the Boss: Restoring Accountability for Labor Standards in Outsourced Work, National Employment Law Project, May 2014. Disponível em: http://www.nelp.org/page/-/Justice/2014/Whos-the-Boss-Restoring-Accountability-LaborStandards-Out-Outsourced-Work-Report.pdf?nocdn=1). Acesso em: 20 abr. 2021.

SEELY, Antony. Self-employment in the construction industry. BRIEFING PAPER Number. 000196, 8 July 2015.

THEBAUD-MONY, Annie. Precarização social do trabalho e resistências para a (re) conquista dos direitos dos trabalhadores na França. Caderno CRH, Salvador, v. 24, n. spe 01, 2011.

UK. Employment Status report. Office of tax simplification. March, 2015. 
URIARTE, Ermida; COLOTUZZO, Natalia. Descentralización, tercerización, subcontratación. Lima: OIT, Proyecto FSAL, 2009.

VAN LIEMT, Gijsbert. Subcontracting in electronics: From contract manufacturers to providers of Electronic Manufacturing Services (EMS). In: Sectoral Activities Programme Working Paper. International Labour Office, Geneva. April 2007. ISBN: 978-92-119906-9. http://ilo.org/wcmsp5/groups/public/---ed dialogue/--sector/documents/publication/wcms 161177.pdf

WRIGHT, C.F. Beyond the employment relationship. Collective bargaining and supply chain coordination. TUC, 2011. 